

\title{
Research
}

\section{Pathway to Paramedicine Program perspectives Part 2: Secondary school students}

\author{
Linda Ross MHIthProfEd, ${ }^{1}$ Jessica Bertucci BSc ${ }^{1}$
}

\author{
Affiliation: \\ ${ }^{1}$ Monash University, Victoria
}

\section{Abstract}

\section{Introduction}

The Pathway to Paramedicine Program offers secondary school students with an interest in the paramedic disciple a unique opportunity to gain insight into both the profession and the training required. This study aimed to evaluate the secondary school students' perspectives of the program.

\section{Methods}

This pilot intervention study using a paper based survey included 14 secondary school students enrolled in the Pathway to Paramedicine Program at Monash University in Melbourne, Victoria. The evaluation survey consisted of a combination of Likert and free text questions.

\section{Results}

All 13 Likert scale items received a median score of 4 (agree) or above. Ten items achieved a maximum median score of 5 (strongly agree). Nine items received a positive score of 4 or 5 from all the students. Participants also indicated they gained insight into the disciple and confidence in their own skills. Fifty percent of the Year 12 participants enrolled in paramedic degrees in 2014.

\section{Conclusion}

The Pathway to Paramedic Program gave secondary school students valuable insight into paramedic practice and helped them make a decision about their future education and career path. The study results showed that the students had a positive perspective of the program, enjoyed and appreciated their interaction with the paramedic student mentors and would recommend the program to others.

\section{Keywords}

paramedic; paramedic as educator; peer assisted learning; PAL; mentor; undergraduate education; careers

Corresponding Author: Linda Ross, linda.ross@monash.edu 


\section{Introduction}

Developments in medical research and technologies associated with the paramedic discipline coupled with demands for high standards of patient care have led to an increasing scope of clinical practice for this profession (1). As a result, over the past 15 years there has been a clear shift in paramedic training, from a hands-on traineeship model to a more specific universitybased education $(2,3)$. Paramedic training and education is now offered at 13 universities across Australia, either through undergraduate or postgraduate degrees (4). The majority of the state ambulance services now accept only graduate students from approved universities in Australia and New Zealand $(2,5)$.

Students undertaking paramedic degrees are provided with a theoretical base, are trained in the use of ambulance equipment and the administration of medications, and learn relevant clinical practice guidelines (6).

Secondary school students hoping to gain entry into the Bachelor of Emergency Health (Paramedic) at Monash University in Melbourne, Victoria or other similar degrees must apply through the Victorian Tertiary Admissions Centre (VTAC) (7). Admission into this degree is based on the applicant's Australian Tertiary Admission Rank (ATAR) score, which measures a student's overall academic achievements and ranks them against other students. Admission also requires satisfactory completion of some prerequisite subjects (English and Maths) (7). Non-school leavers can also apply through VTAC and are considered based on a set of criteria that take into account previous study and relevant industry experience.

The Pathway to Paramedicine Program is therefore not a direct pathway into the Bachelor of Emergency Health (Paramedic) at Monash University nor does it have any bearing on future entry into the course or university. What the program does provide however, is an opportunity for those secondary school students with an interest in a career in paramedicine with information and experience that may assist them in making an informed decision.

\section{The Pathway to Paramedicine Program}

The Pathway to Paramedicine Program is very similar to other peer assisted learning (PAL) programs, and has second year paramedic students training and mentoring secondary school students. Peer assisted learning programs have been shown to be an extremely valuable tool in most educational settings (8-10). They create a unique learning environment, which is less hostile and promotes a greater knowledge exchange, especially for the mentees $(6,9)$. Studies have shown that PAL programs result in increased academic performance and decreased fail rate among mentee participants when compared to nonparticipants (11).

Further details regarding the structure and content of the
Pathway to Paramedicine Program can be found in the paper, Pathway to Paramedicine Program Perspectives - Part 1:

Paramedic students (12). The aim of this study was to evaluate the secondary school students' perspectives on the Pathway to Paramedicine Program.

\section{Methods}

A pilot intervention study using paper-based surveys was administered on the final day of the Pathway to Paramedicine Program at the Peninsula Campus of Monash University in Victoria.

\section{Participants}

A total of 21 secondary school students from various secondary schools in Melbourne, Victoria, participated in the program.

The secondary school students were recruited through Monash University open days and careers information sessions. Those interested in studying the Bachelor of Emergency Health (Paramedic) or similar courses, and a career in paramedicine or similar were invited to sign up for the program. Participants were selected in order of expression of interest via email to the program co-ordinator. The program was voluntary and free of charge. The students were in years 10, 11 or 12 and if aged less than 18 years, required parental consent to participate in the program.

\section{Instrumentation}

The Pathway to Paramedicine Evaluation (PPE) survey was developed by the authors. It consisted of 13 questions utilising a five point Likert scale with 1 (strongly disagree) to 5 (strongly agree) and two free text questions. The evaluation asked the secondary school participants to rate their perceptions of the program in relation to their own skills, their experience of being taught by paramedic students, and their overall experience.

\section{Procedures}

On the final day of the program, the secondary school students were asked to complete the PPE. The purpose of the evaluation was explained to all participants and completion was voluntary. Year 12 participants were also contacted via email at the beginning of the following year (2014) to gather information about their enrolment in related courses.

\section{Data analysis}

The Statistical Package for the Social Sciences Version 20.0 (SPSS) was used for entry, storage, retrieval and analysis of the quantitative and demographic data. The two free-text questions were transcribed verbatim. The authors performed a thematic analysis and collaborated to identify major themes. 


\section{Ethics}

Monash University Human Ethics Research Committee (MUHREC) granted ethics approval for this project.

\section{Results}

\section{Participant demographics}

Of the 21 secondary student participants, a total of 14 completed the PPE $(n=14)$. Of these, $78.6 \%(n=11)$ were female and $57.1 \%(n=8)$ were studying Year 12 . The majority were aged less than 18 years $(n=11,78.6 \%)$ and the mean age was 17 years. See Table 1 for full demographic results.

\section{Secondary school student evaluation}

All 13 Likert scale items on the PPE received a median score of 4 (agree) or above. Ten items achieved a maximum median score of 5 (strongly agree). Nine items received a positive score of 4 or 5 from all students. Item 13, 'The second year paramedic students were willing to answer questions', had the highest result with all participants scoring this item 5 . Six items had an interquartile range of $5-5$. See Table 2 for overall evaluation results.

Table 1. Demographic results

\begin{tabular}{|c|c|c|c|}
\hline \multicolumn{2}{|c|}{ Demographics } & $\begin{array}{c}\text { Frequency } \\
\mathrm{n}=\end{array}$ & $\begin{array}{c}\text { Percentage } \\
\%\end{array}$ \\
\hline \multirow{3}{*}{ Gender } & Female & 11 & 78.6 \\
\cline { 2 - 4 } & Male & 3 & 21.4 \\
\hline \multirow{4}{*}{ Age } & 15 & 1 & 7.1 \\
\cline { 2 - 4 } & 16 & 2 & 14.3 \\
\cline { 2 - 4 } & 17 & 8 & 57.1 \\
\cline { 2 - 4 } & 18 & 3 & 21.4 \\
\hline \multirow{3}{*}{ Year Level } & 10 & 3 & 21.4 \\
\cline { 2 - 4 } & 11 & 3 & 21.4 \\
\cline { 2 - 4 } & 12 & 8 & 57.1 \\
\hline
\end{tabular}

Table 2. Overall evaluation results

\begin{tabular}{|l|c|}
\hline \multicolumn{1}{|c|}{ Question } & Md (1QR) \\
\hline The Pathway to Paramedicine Program has:- & $4.5(4-5)$ \\
\hline 5. Helped me decide which course/s to apply for & $4(4-5)$ \\
\hline 6. Helped me decide on the type of career to pursue & $5(5-5)$ \\
\hline 7. Given me a good introduction to the Bachelor of Emergency Health (Paramedic) Degree & $4(4-5)$ \\
\hline 8. Increased my confidence in being able to offer first aid if necessary & $5(4-5)$ \\
\hline 9. Increased my knowledge and skills in relation to medical emergencies & \\
\hline The second year paramedic students were:- & $5(5-5)$ \\
\hline 10. Friendly, engaging and helpful & $5(5-5)$ \\
\hline 11. Knowledgeable & $5(4-5)$ \\
\hline 12. Very good at explaining key concepts and skills & $5(5-5)$ \\
\hline 13. Willing to answer questions & $5(5-5)$ \\
\hline 14. Supportive and encouraging & \\
\hline Overall:- & $5(4-5)$ \\
\hline 15. The Pathway to Paramedicine Program was very well organised & $5(4.8-5)$ \\
\hline 16. I enjoyed the Pathway to Paramedicine Program & $5(5-5)$ \\
\hline $\begin{array}{l}\text { 17. I would recommend the Pathway to Paramedicine Program to other students interested in the } \\
\text { Bachelor of Emergency Health (Paramedic) Degree }\end{array}$ & \\
\hline
\end{tabular}

Note: Not included in this table are the demographic questions (Q1-4), and the free text questions (Q18-19) 


\section{Qualitative themes}

A thematic analysis found four major themes from the PPE free text responses. The major themes identified were:

- The program gave the students an insight into paramedic practice

'This really gave me an insight to paramedicine and nursing' (participant 14)

- It helped reinforce first aid and CPR skills

'I definitely learnt and gained more confidence with first aid' (participant 11)

- Helped participants decide what to pursue at university 'The program has helped me decide that this is what I really want to do' (participant 2)
- The paramedic students were easy to talk to and knowledgeable

'It was good being able to ask any questions to the student paramedics as they were knowledgeable and friendly' (participant 7).

\section{Follow-up results}

Of the eight Year 12 student participants, 50\% ( $n=4)$ enrolled in a university paramedicine degree in 2014 and $12.5 \%$ $(n=1)$ enrolled in a university nursing degree. The remaining participants ( $n=3,37.5 \%)$ enrolled in a TAFE (Technical and Further Education) program as a pathway into a university paramedicine degree for 2015. See Table 3 for full results.

Table 3. Follow-up results

\begin{tabular}{|c|c|c|c|}
\hline $\begin{array}{c}\text { Year 12 } \\
\text { Participants }\end{array}$ & $\begin{array}{c}\text { Enrolled in a } \\
\text { Paramedicine } \\
\text { Degree for 2015 }\end{array}$ & $\begin{array}{c}\text { Enrolled in a } \\
\text { Nursing Degree } \\
\text { for 2015 } \\
\text { program as a } \\
\text { pathway into a } \\
\text { University } \\
\text { Paramedic Degree } \\
\text { in 2016 }\end{array}$ \\
\hline 1 & $\mathrm{X}$ & & $\mathrm{X}$ \\
\hline 2 & & & \\
\hline 3 & $\mathrm{X}$ & & $\mathrm{X}$ \\
\hline 4 & $\mathrm{X}$ & & $\mathrm{X}$ \\
\hline 5 & $\mathrm{X}$ & & 3 \\
\hline 6 & & & \\
\hline 7 & & $\mathrm{X}$ & \\
\hline 8 & 4 & 1 & \\
\hline Total & & & \\
\hline
\end{tabular}

\section{Discussion}

The aim of this study was to determine the secondary school students' perspective of the Pathway to Paramedicine Program. It is evident from the literature that PAL models are a valuable tool in undergraduate education and benefit both mentors and mentees alike $(1,6)$. The Pathway to Paramedicine Program was no different, with an overwhelmingly positive response from the secondary school students. While the evaluation results were pleasing, they can only be considered an indication of the value and success of the program due to the small sample size.

One of the programs initial purposes was to give the secondary school students an insight into paramedic practice and help inform their decisions about future career and study options. Paramedic practice is a unique and specific field and the majority of secondary students were not fully aware of what a career as a paramedic entailed. The results indicate this objective was met. The items pertaining to these issues in the PPE (5-7) all achieved a median of over 4 and this was reiterated in the free text responses with students voicing opinions on how the program had given them insight into paramedic practice and helped with career choices. This was also demonstrated by the follow up results of the Year 12 participants. Of the eight Year 12 participants, seven were accepted into either a paramedicine degree at university or a TAFE program as a pathway into a paramedicine degree.

The results also indicated that the secondary school students were very receptive to the paramedic students acting as educators. PPE items 10-14 and the free text responses showed that the students found the paramedic students were knowledgeable, supportive, friendly, easy to talk to and willing to answer any questions. A good relationship between mentors and mentees has been shown to enable a more suitable learning environment and affect the success of programs such as these (9). A good relationship between peers in PAL programs has also been shown to foster a less intimidating learning environment with peers not having the same authority as a traditional classroom teacher $(6,9)$. This less formal learning environment and a positive relationship between mentors and mentees allowed the students to gain skills and confidence with less fear of making mistakes. 
Best et al also found mentors increased their skills and confidence after participation in PAL programs (6). The small ratio of mentors to secondary school students and the consistency of mentors throughout the program could also be a contributing factor in these results.

The program also allowed the secondary school students to reinforce their own first aid and medical knowledge and skills. They were able to build their confidence in administering such skills while being able to relate them back to paramedic practice. Some of the participants have had previous exposure to first aid and cardiopulmonary resuscitation through training with organisations such as St Johns Ambulance or Surf Life Saving. Reinforcing these skills in the program demonstrated the importance of these skills in paramedic practice and gave students more confidence in performing them. The students were also very pleased with the new clinical knowledge and skills they gained through the program, and this will hopefully serve as valuable life skills even if a career in paramedicine does not eventuate.

Overall, the secondary school students had a very positive perspective of the program. In particular, it was pleasing to see that the secondary school students enjoyed the program and would happily recommend it to other students who are interested in the Bachelor of Emergency Health (Paramedic) degree. This positive result justifies the implementation of the Pathway to Paramedicine Program in the future.

\section{Future research}

Similar to the paper, Pathway to Paramedicine Perspectives - Part 1: Paramedic students, the overwhelming positive

\section{References}

1. Williams B, Brown T, Onsman A. Is the Australian paramedic discipline a full profession? J Emerg Prim Health Care 2010;8(1):3.

2. Joyce CM, Wainer J, Pitermann L, Wyatt A, Archer F. Trends in the paramedic workforce: a profession in transition. Australian Health Review 2009;33(4):533-40.

3. Edwards D. Paramedic preceptor: work readiness in graduate paramedics. Clin Teach 2011;8(2):79-82.

4. Paramedics Australasia. University Courses 2014. Available at: www.paramedics.org/university-courses/ [Accessed January 15 2014].

5. O'Meara P. Searching for paramedic academics: vital for our future, but nowhere to be seen! Australasian Journal of Paramedicine 2012;4(4):1.

6. Best G, Hajzler D, Ivanov T, Limon J. Peer mentoring as a strategy to improve paramedic students' clinical skills. Journal of Peer Learning 2008;1(1):13-25. perspective of the program justifies further research with a larger sample size. Motivation and determinants to enter such a career path are areas to be considered in future research.

\section{Limitations of this study}

The results of this pilot study are not generalisable due to the small sample size.

\section{Conclusion}

The Pathway to Paramedic Program provided secondary school students with an insight into the Bachelor of Emergency Health (Paramedic) and paramedic practice which helped them make a decision about their future education and career paths. The results of the pilot study showed that the students had a positive perspective of the program, enjoyed and appreciated their interaction with paramedic student mentors and would recommend the program to others.

\section{Acknowledgements}

We would like to thank the students who took the time to participate in the study.

\section{Competing interests}

The authors declare they have no competing interests. Each author of this paper have completed the ICMJE conflict of interest statement.

7. Monash University. Admissions information for domestic students, Bachelor of Emergency Health (Paramedic)

2013. Available at: www.monash.edu.au/study/ coursefinder/course/3445/domestic-requirements. $\mathrm{html}$ ?courseview=domestic [Accessed January 15 2014].

8. Silbert BI, Lam SJ, Henderson RD, Lake FR. Students as teachers. Med J Aust 2013;199(11):757.

9. Topping KJ, Ehly SW. Peer assisted learning: a framework for consultation. J Educ Psychol Consult 2001;12(2):113-32.

10. Henning JM, Weidner TG, Marty M. Peer assisted learning in clinical education: Literature review. Athl Train Educ J 2008;3(3):84-90.

11. Hryciw DH, Tangalakis K, Supple B, Best G. Evaluation of a peer mentoring program for a mature cohort of first-year undergraduate paramedic students. Adv Physiol Educ 2013;37(1):80-4.

12. Ross L, Bertucci J. Pathway to Paramedicine Program Perspectives - Part 1 Paramedic Students. Australasian Journal of Paramedicine 2014;11(6). 